
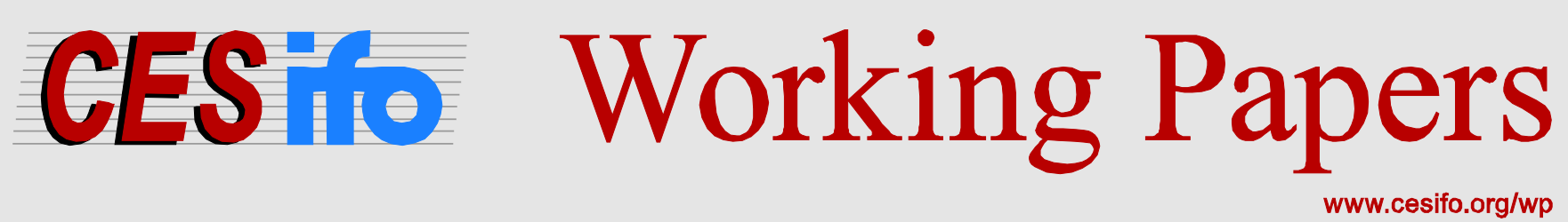

\title{
Continuous Logit Polycentric City Model
}

\author{
Matthias Wrede
}

\author{
CESIFO WORKING PAPER NO. 4580 \\ CATEGORY 4: LABOUR MARKETS \\ JANUARY 2014
}

An electronic version of the paper may be downloaded

- from the SSRN website:

- from the RePEc website:

- from the CESifo website:

wWw.SSRN.com

Www.RePEc.org

www.CESifo-group.org/wp

\section{CESifo}




\title{
Continuous Logit Polycentric City Model
}

\begin{abstract}
This paper analyzes a closed, essentially linear polycentric city with homogenous households who probabilistically select their workplace and residence locations. The study utilizes a continuous logit model to describe household location choices. In contrast to the classic urban model with deterministic location choices, the continuous logit model predicts noticeable direct effects of more than one workplace on land rents, asymmetry of the land rent schedule around secondary business districts, incomplete segregation of citizens who work in different business centers and, therefore, cross commuting, and incomplete segregation of workers and farmers.
\end{abstract}

JEL-Code: R130, R140, D110.

Keywords: urban spatial equilibrium, polycentric city, probabilistic location choices, continuous logit model, cross commuting.

\author{
Matthias Wrede \\ University of Erlangen-Nuremberg \\ School of Business and Economics \\ PO Box 3931 \\ Germany - 90020 Nuremberg \\ matthias.wrede@fau.de
}

This version: October 2013 


\section{Introduction}

In the classic monocentric city model of Alonso (1964), Mills (1967), and Muth (1969), households conditionally select their residences based on their workplace and optimally trade off commuting costs and land prices. ${ }^{1}$ Within this framework, polycentric cities can be considered to be unions of monocentric cities in which workers commute to the business district where wages in excesss of commuting costs are highest. ${ }^{2}$ However, because the classic approach cannot easily explain cross commuting in a polycentric city, which is a common arrangement in which two commuters would benefit from switching houses, extended or alternative models are needed. ${ }^{3}$

Anas (1990) considered a monocentric city where utility functions contained additive idiosyncratic utility constants that differed among households. This type of random taste heterogeneity implies that household choices can only be probabilistically determined. In partitioning the metropolitan area into a large number of smaller areas, Anas (1990) applied a discrete choice model and used a multinomial logit model to describe the location choices of households. Assuming that common utilities do not differ across locations, in discrete space and with one type of household, the multinomial logit model asymptotically converges to the Alonso-Mills-Muth model. Anas and Kim (1996), Anas and Rhee (2006), and others have extended this model to allow for polycentricity, consumption externalities and production externalities. Tscharaktschiew and Hirte (2010) studied cross commuting of one and two worker households. However, the multinomial logit model in discrete space lacks the straightforwardness of the Alonso-Mills-Muth model and immediately becomes analytically intractable and requires extensive simulations.

To simultaneously allow for a richer and more realistic spatial pattern than the Alonso-

\footnotetext{
${ }^{1}$ For an overview of the Alonso-Mills-Muth model, see, Brueckner (1987) and Fujita (1989).

${ }^{2}$ The body of literature on polycentric cities focused on the emergence of centers and on the effects of cities on behavior and policy. For example, Fujita and Ogawa (1982) analyzed the formation and location of subcenters in a linear city; Lucas and Rossi-Hansberg (2002) analyzed a circular city in which businesses and housing can be located anywhere in the city; and Wrede (2009) considered second-best commuting subsidies in a linear duocentric city.

${ }^{3}$ The existence of local amenities $(\mathrm{Ng}, 2008)$ and two-earner households may explain only part of observed cross-commuting. Market imperfections, especially job-search imperfections, and moving costs likely contribute more (Van Ommeren and Van der Straaten, 2005).
} 
Mills-Muth model and to preserve tractability as far as possible, this paper uses the continuous logit model proposed by McFadden (1976), Ben-Akiva and Watanatada (1981), and Ben-Akiva, Litinas, and Tsunokawa (1985) as a tool to analyze the location and workplace choices of homogeneous households within a metropolitan area. The continuous logit model is a probabilistic choice model for a continuum of alternatives, which has not yet been used in urban general equilibrium analysis with endogenous prices. The continuous logit model can also be considered to be a limiting case of the discrete logit model.

The purpose of this paper is to analyze the urban spatial patterns in continuous space in a closed polycentric city with one or more business centers in given locations and to provide explicit solutions for land rents and land use. ${ }^{4}$ The resulting spatial structure substantially differs from an urban model with deterministic location choices. First, employees who work in different business centers are incompletely segregated. Because workers must achieve the same equilibrium utility in the presence of deterministic location choices, land rent differences cannot simultaneously compensate for different levels of commuting costs and wages. If location choices are probabilistic, the deterministic part of equilibrium utility varies across locations. Compensating for differences in the deterministic aspect of the utility is only partially necessary. Second, land rents are higher in areas where more workplaces are nearby than in areas that are close to only one workplace. Land rents are asymmetric around secondary business districts. Third, in the city's outer areas, only a fraction of the available land is used by city dwellers and the land rent is equal to the land opportunity costs. In the classic model, city dwellers are unwilling to live in an area where workers are not compensated for increasingly long commutes because the land rent is equal to the opportunity costs of the land. With probabilistic choices, a small fraction of workers accepts incomplete compensation for additional commuting costs.

Based on this model, several empirically testable hypotheses emerge. First, cross commuting occurs in metropolitan areas. Second, land prices are affected by the accessibility of workplaces rather than only the distance to the business district with the highest wage in excess of commuting costs. Third, land prices are asymmetric around secondary business districts. The first hypothesis is obviously compatible with observed commuting behavior,

\footnotetext{
${ }^{4}$ Wrede (2013) applies the continuous logit model to analyze the spatial equilibrium in a monocentric city with multiple income classes.
} 
since there is a great deal of evidence for cross commuting in cities (see, Hamilton, 1982; Small and Song, 1992). As for the second and the third hypothesis, recent research has provided convincing evidence for a workplace accessibility effect (see, Osland and Thorsen, 2008; Ahlfeldt, 2011).

\section{Continuous logit polycentric city model}

The model considers land use in a polycentric city that is modeled as a star with $m$ edges, $m \geq 2$, where the central business district (CBD) is the central node, indicated by its location, 0 . At each edge, $n$ secondary business districts (SBDs), with $n \geq 1$, are located, where $S B D_{k}$ is located at distance, $d_{k}$, to the CBD, $k=1, \ldots, n$. Without loss of generality, workplaces are arranged in increasing order: $d_{0}=0<d_{1} \cdots<d_{n}$. The spatial extent of every business district is normalized to 0 . For notational simplicity, we assume perfect symmetry regarding edges. Distributions of SBDs, wages, and land rents are identical for all edges. At each edge, land is available along a straight line with unit width ranging from 0 to $\infty$. All land parcels are identical and ready for residential land use and numerous externalities are absent. Locations are identified by their Euclidian distance, $r$, to the CBD. The city hosts total population $N$ and spans at every edge from 0 to $b$, with $N>0, b \geq N / m$ and $b>d_{n}$. The restrictions on the boundary imply that all SBDs are located within the boundaries of the city and that part of the city's area may not be used for housing. The city's boundary, $b$, is determined by an exogenous institution. As $b$ may be very large, this assumption is not very restrictive. Every citizen commutes to a workplace that is located either in the CBD or in one of the SBDs, inelastically supplies one unit of labor, earns only labor income, consumes the numéraire good at price 1, and uses one unit of land at a location of his or her own choice. Land is used as a proxy for housing. Absent landowners are only willing to rent to citizens if the land rent for one unit of land does not fall short of their opportunity costs, $R_{A}$. Opportunity costs are determined by exogenously provided unlimited land demands of farmers, up to the land price $R_{A}$. Depending on distance, the land rent, $R(r)$, equalizes demand and supply in a perfectly competitive rental market. Linear round-trip commuting costs, $T=t q$, with $t>m / N$, are assumed, where $q$ indicates total (one-way) commuting distance. If the 
worker lives at the same edge where he or she works and if he or she works in SBD $k$, then one-way commuting distance is $q=\left|r-d_{k}\right|$; if he or she lives and works at different edges, $q=r+d_{k}$ holds. The wage at workplace $k$ is denoted by $w_{k}$ and exogenously given. A worker living $r$ miles from the CBD at edge $i$ and working in business district $k$ at edge $j$ achieves the (deterministic) utility, which is measured in terms of the numéraire, $u(r, i, j, k)=w_{j}-t q-R(r)$. The deterministic utility of a worker employed in the CBD is denoted by $u(r, i, 1,0)=w_{0}-t r-R(r)$.

Following McFadden (1976), Ben-Akiva and Watanatada (1981), and Ben-Akiva, Litinas, and Tsunokawa (1985), a continuous logit model is applied to describe location choices. The total utility is assumed to consist of the deterministic utility, $u(r, i, j, k)$, and an idiosyncratic location taste constant, $\epsilon(r, i, j, k)$,

$$
v(r, i, j, k)=u(r, i, j, k)+\epsilon(r, i, j, k) \text { for all } i, j \in\{1, \ldots, m\}, k \in\{0, \ldots, n\},
$$

with $j=1$ if $k=0$. Each $\epsilon(r, i, j, k)$ is a random variable that is independently and identically (i.i.d.) extreme-value distributed for all choice sets. ${ }^{5}$ The symmetry assumption implies $u(r, i, j, k)=u(r, j, i, k)$ and $u(r, i, j, k)=u(r, l, j, k)$, for all $i, j, l \in\{1, \ldots, m\}$, $l \neq j$, and $k \in\{1, \ldots, n\}$.

Considering that the amount of available land is constant across space and after appropriately normalizing the variance of the extreme-value distribution, the logit choice density function can be written as ${ }^{6}$

$$
\begin{aligned}
p(r, i, j, k) & =\frac{I(r, i, j, k) e^{u(r, i, j, k)}}{P}, \\
\text { where } P & =\sum_{i=1}^{m}\left[\int_{0}^{b} I(s, i, 1,0) e^{u(s, i, 1,0)} d s+\sum_{j=1}^{m} \sum_{k=1}^{n} \int_{0}^{b} I(s, i, j, k) e^{u(s, i, j, k)} d s\right],
\end{aligned}
$$

$r \in[0, b], i, j \in\{1, \ldots, m\}, k \in\{0, \ldots, n\}$, with $j=1$ if $k=0 . I(r, i, j, k)$ is an indicator function of commuting and housing affordability. The worker either can afford commuting and housing, $I(r, i, j, k)=1$, or not, $I(r, i, j, k)=0$, implying

$$
I(r, i, j, k)= \begin{cases}1 & \text { if } w_{k} \geq t q+R(r), \\ 0 & \text { otherwise }\end{cases}
$$

\footnotetext{
${ }^{5}$ Compared to the discrete choice model with a finite set of opportunities, the i.i.d. assumption is clearly more restrictive in the continuous choice model, but the method still provides a useful proxy.

${ }^{6}$ The first term in the squared brackets captures employees working in the CBD.
} 
A minimum requirement for affordability is that the wage at every workplace does not fall short of the land opportunity costs. To simplify, wages are assumed to exceed the sum of land opportunity costs and maximum commuting costs within the city: $w_{k}>R_{A}+t\left(d_{k}+b\right)$, for $k=0, \ldots, n$. (Expected) urban land demand at distance $r$ and edge $i$ is defined as

$$
L(r, i)=N\left[p(r, i, 1,0)+\sum_{j=1}^{m} \sum_{k=1}^{n} p(r, i, j, k)\right], \quad \text { where } L(r, i) \geq 0,
$$

where $p(r, i, 1,0)$ captures individuals employed in the CBD. Symmetry implies $L(r, i)=$ $L(r)$, for $i=1, \ldots, m$. By construction, aggregate urban land use is equal to total population size, i.e., $m \int_{0}^{b} L(r) d r=N$.

Definition 1 For uniform land use in a polycentric city with an exogenously determined border, b, a (stochastic) spatial urban equilibrium is defined as a land rent function, $R(r)$, with $R \in \Re_{0}^{+}$, for $r \in[0, b]$, and a set of strictly positive wages, $\left\{w_{0}, \ldots, w_{n}\right\}$, with the following properties: All agents take all wages, the continuum of land prices, and the consumption good price normalized to 1 as given; all citizens select locations and workplaces according to the logit choice density function (2); all citizens live somewhere and work in some business district within the boundaries of the city; at every distance, $r$, landowners maximize revenue and total (expected) land demand equals supply.

In equilibrium, urban land use is bounded from above so that $L(r) \leq 1$. Perfect competition in the land market ensures that opportunity costs never exceed land rents (i.e, $R(r) \geq R_{A}$ ), and land rents exceed the land opportunity costs only if citizens use the entire available land (i.e., $R(r)>R_{A} \Rightarrow L(r)=1$ and $L(r)<1 \Rightarrow R(r)=R_{A}$ ).

Assuming $I(r, i, j, k)=1$, for all $i, j \in\{1, \ldots, m\}, k \in\{0, \ldots, n\}$, using symmetry and the definition of $u(r, i, j, k)$, urban land demand at distance $r$, with $d_{j} \leq r$ for $j=0, \ldots, i$, and $d_{j}>r$ for $j=i+1, \ldots, n$, can be written as

$$
L(r)=\frac{N}{e^{R(r)} P}\left[e^{w_{0}-t r}+\sum_{j=1}^{i} e^{w_{j}-t\left(r-d_{j}\right)}+\sum_{j=i+1}^{n} e^{w_{j}-t\left(d_{j}-r\right)}+(m-1) \sum_{j=1}^{n} e^{w_{j}-t\left(d_{j}+r\right)}\right] .
$$

The first term in the squared brackets covers employees of the $\mathrm{CBD}$, the second and the third terms cover employees of SBDs at the same edge, and the fourth term covers employees of SBDs at other edges. Because Equation (5) implies that $H(r):=\ln L(r)+R(r)$ 
is a continuous function of distance, $L(r)$ is continuous if $R(r)$ is continuous, and vice versa. For $r \geq d_{n}, H(r)$ is a decreasing function of distance. Thus, if $L(r)$ is constant, $R(r)$ continuously decreases with distance; if $R(r)$ is constant, $L(r)$ continuously decreases with distance. In the case of $r<d_{n}, H(r)$ and, therefore, $R(r)$ may increase if distance increases.

Suppose now that a critical location, $\bar{r}$, exists such that $R(\bar{r})=R_{A}, L(\bar{r})=1$, and $\bar{r}>d_{n}$. Thus, the critical location, $\bar{r}$, where the land price is equal to the land opportunity costs and urban land use is equal to total land supply, is farther away from the CBD than the outermost SBD. A special case is $\bar{r}=b=N / m$ which represents when the entire city area is used for housing. Because $R(r) \geq R_{A}, L(r) \leq 1$, and $H(r)$ is a decreasing function of distance for $r \geq d_{n}, R(r)=R_{A}$ and $L(r)<1$ for $r \in(\bar{r}, b]$ and $R(r)>R_{A}$ and $L(r)=1$ for $r \in\left[d_{n}, \bar{r}\right)$. Suppose further that the inner area of the city is a rather attractive living area (i.e., $R(r)>R_{A}$ and $L(r)=1$ also for $r \in\left[0, d_{n}\right)$ ) such that the critical location, $\bar{r}$, divides the city into two different parts: The inner area where the land rent exceeds the land opportunity costs is completely used by city dwellers, while the outer area where farmers' willingness to pay determines the land rent is partially used by farmers.

Definition 2 A spatial urban equilibrium with an urban core and a mixed-use periphery is defined as a (stochastic) spatial urban equilibrium where a critical location, $\bar{r}$, exists such that (a) $R(r)>R_{A}$ and $L(r)=1$ for $r \in[0, \bar{r})$, (b) $R(\bar{r})=R_{A}$ and $L(\bar{r})=1$, and (c) $R(r)=R_{A}$ and $L(r)<1$ for $r \in(\bar{r}, b]$.

The land market equilibrium conditions for $\bar{r}, R(\bar{r})=R_{A}$ and $L(\bar{r})=1$, can be used to solve for $N / P$, which can be used to calculate urban land use in the outer area and the land rent schedule in the inner area. Substituting for $N / P$, urban land use in the outer area turns out to be exponential, i.e.,

$$
L(r)=e^{t(\bar{r}-r)}<1, \quad \text { for } r \in(\bar{r}, b] .
$$

Equation (6) can be used to determine the critical location, $\bar{r}$. Solving

$$
\int_{0}^{b} L(r) d r=\bar{r}+\int_{\bar{r}}^{b} L(r) d r=\bar{r}-\frac{e^{t(\bar{r}-b)}-1}{t}=\frac{N}{m}
$$


leads to

$$
\bar{r}=\frac{N}{m}-\frac{1+\mathcal{W}\left[-e^{-1-t(b-N / m)}\right]}{t} \in\left(\frac{N}{m}-\frac{1}{t}, \frac{N}{m}\right],
$$

where $\mathcal{W}$ is the principal value of the Lambert $\mathrm{W}$ function. ${ }^{7}$ Note that $\bar{r}=N / m$ if $b=N / m$.

Solving Equation (5) for $R(r)$ and substituting for $N / P$, the land rent in the area between the outermost workplace and the critical location, $\bar{r}$, can be determined as

$$
R(r)=R_{A}+t(\bar{r}-r), \quad \text { for } r \in\left[d_{n}, \bar{r}\right] .
$$

In this area, the land rent is a linear and decreasing function of distance to the CBD. For locations closer to the CBD than the outermost SBD, using the same procedure, the non-linear land rent function can be calculated as

$$
\begin{aligned}
R(r)=R_{A} & +t(\bar{r}-r) \\
& +\ln \left[\frac{e^{w_{0}}+\sum_{j=1}^{i} e^{w_{j}+t d_{j}}+\sum_{j=i+1}^{n} e^{w_{j}-t\left(d_{j}-2 r\right)}+\sum_{j=1}^{n} e^{w_{j}-t d_{j}}}{e^{w_{0}}+\sum_{j=1}^{n} e^{w_{j}+t d_{j}}+\sum_{j=1}^{n} e^{w_{j}-t d_{j}}}\right],
\end{aligned}
$$

for $r \in\left[0, d_{n}\right)$, and $d_{j} \leq r$ for $j=0, \ldots, i$, and $d_{j}>r$ for $j=i+1, \ldots, n$,

with

$$
\begin{aligned}
\frac{d R(r)}{d r} & =-t \frac{e^{w_{0}-t r}+\sum_{j=1}^{i} e^{w_{j}+t\left(d_{j}-r\right)}-\sum_{j=i+1}^{n} e^{w_{j}-t\left(d_{j}-r\right)}+\sum_{j=1}^{n} e^{w_{j}-t\left(d_{j}+r\right)}}{e^{w_{0}-t r}+\sum_{j=1}^{i} e^{w_{j}+t\left(d_{j}-r\right)}+\sum_{j=i+1}^{n} e^{w_{j}-t\left(d_{j}-r\right)}+\sum_{j=1}^{n} e^{w_{j}-t\left(d_{j}+r\right)}} \\
& \in(-t, t) .
\end{aligned}
$$

Because the term in squared brackets in Equation (10) is lower than 1, the land rent in the city's inner areas is lower than $R_{A}+t(\bar{r}-r)$. As $d R(r) / d r<t$, a sufficient, but not necessary condition for $R(r)>R_{A}$ in the area $\left[0, d_{n}\right)$ is $\bar{r}>2 d_{n}$.

By differentiating the land rent function (10) with respect to wages, it can be shown that the land rent at a particular location increases if the wages in the CBD or in one of the SBDs that are located closer to the CBD increases; however, the land rent may decrease if the wage in one of the SBDs that are located far away from the CBD increases.

Contrary to an urban equilibrium with deterministic choices, the land rent schedule is generally asymmetric around the SBDs because employment opportunities are asymmetric

\footnotetext{
${ }^{7}$ Because $-1 / e \leq-e^{-1-t(b-N / m)}<0$, the Lambert $\mathrm{W}$ function has one negative real value if $b=N / m$ and two negative real values otherwise; here, the real value at the principal branch is used.
} 
around the SBDs. Because $d R(r) / d r<t$ for $r \in\left[0, d_{n}\right)$ and $d R(r) / d r=-t$ for $r \in\left(d_{n}, \bar{r}\right]$, the land rent schedule is unambiguously asymmetric around the outermost SBD. For $k<n$ and a small $\Delta>0$,

$$
\begin{aligned}
& R\left(d_{k}-\Delta\right)-R\left(d_{k}+\Delta\right) \\
& =2 t \Delta+\ln \left[e^{w_{0}}+\sum_{j=1}^{k-1} e^{w_{j}+t d_{j}}+\sum_{j=k}^{n} e^{w_{j}-t\left[d_{j}-2\left(d_{k}-\Delta\right)\right]}+\sum_{j=1}^{n} e^{w_{j}-t d_{j}}\right] \\
& \quad-\ln \left[e^{w_{0}}+\sum_{j=1}^{k} e^{w_{j}+t d_{j}}+\sum_{j=k+1}^{n} e^{w_{j}-t\left[d_{j}-2\left(d_{k}-\Delta\right)\right]}+\sum_{j=1}^{n} e^{w_{j}-t d_{j}}\right]
\end{aligned}
$$

Asymmetry (i.e., $\left.R\left(d_{k}-\Delta\right) \neq R\left(d_{k}+\Delta\right)\right)$ is very likely. Because

$$
R\left(d_{k}-\Delta\right)>R\left(d_{k}+\Delta\right) \Leftrightarrow e^{w_{0}}+\sum_{j=1}^{k} e^{w_{j}+t d_{j}}+\sum_{j=1}^{n} e^{w_{j}-t d_{j}}>\sum_{j=k+1}^{n} e^{w_{j}-t\left(d_{j}-2 d_{k}\right)},
$$

$R\left(d_{k}-\Delta\right)>R\left(d_{k}+\Delta\right)$ is more likely, the larger $k$ is. For SBDs far away from the CBD, the land rent decreases more rapidly in the direction of the city's boundary than in the direction of the city center.

The following proposition summarizes the primary findings on the properties of the spatial urban equilibrium with an urban core and a mixed-use periphery.

Proposition 1 If a spatial urban equilibrium with an urban core and a mixed-use periphery where the critical location, $\bar{r}$, is defined by Equation (8) exists, it has the following properties:

(i) Outside location $\bar{r}$, urban land use is a declining exponential function of distance defined by Equation (6).

(ii) In the area between the outermost $S B D$ and location $\bar{r}$, the land rent is a decreasing linear function of distance defined by Equation (9). In the area between the CBD and the outermost SBD, the land rent is a non-linear function of distance defined by Equation (10). (iii) An increase in the wage at the $C B D$ or in one of the $S B D$ s does not affect the critical location, $\bar{r}$, or the land rent in the outer area $\left[d_{n}, b\right]$. An increase in the wage in business district $j, 0<j<n$, increases the land rent in the area $\left[d_{j}, d_{n}\right)$, but the increase may decrease the land rent in same parts of the area $\left[0, d_{j}\right)$.

(iv) The land rent schedule is asymmetric around SBDs. For SBDs far away from the 



Figure 1: Urban land use (left chart) and land rent for a symmetric wage distribution (middle chart) and an asymmetric wage distribution (right chart)

$C B D$, the land rent decreases more rapidly in the direction of the city's boundary than in the direction of the city center.

To ensure the existence of equilibrium, Equation (10) defines together with $R(r)>R_{A}$ for $r \in\left[0, d_{n}\right)$ a lower-bound for the wage at the CBD that is denoted by $w_{0}^{-}$, where $w_{0}^{-}$is the lowest non-negative real number that satisfies

$$
e^{w_{0}^{-}}>\sum_{j=i+1}^{n} e^{w_{j}+t d_{j}}\left[\frac{1-e^{t\left(\bar{r}+r-2 d_{j}\right)}}{e^{t(\bar{r}-r)}-1}\right]-\sum_{j=1}^{n} e^{w_{j}-t d_{j}}-\sum_{j=1}^{i} e^{w_{j}+t d_{j}} .
$$

The following proposition compiles the necessary conditions for the existence of the spatial urban equilibrium with an urban core and a mixed-use periphery.

Proposition 2 If $b \geq N / m$ and $N / m-\left\{1+\mathcal{W}\left[-e^{-1-t(b-N / m)}\right]\right\} / t>d_{n}$, sufficiently high wages, $\left\{w_{0}, \ldots, w_{n}\right\}$, with $w_{0} \geq w_{0}^{-}$, exist such that a spatial urban equilibrium with an urban core and a mixed-use periphery where the critical location, $\bar{r}$, is defined by Equation (8) exists.

For a linear city with $2 \times 3$ SBDs, i.e., $m=2$ and $n=3$, and arbitrarily selected parameters $R_{A}=1, t=1, N=10, b=7.5, d_{1}=1, d_{2}=2, d_{3}=3$, and $w_{1}=w_{2}=w_{3}=$ $20, \bar{r}=4.03115$, Figure 1 shows urban land use, $L(r)$, and the land rent schedule, $R(r)$, for a symmetric wage distribution (i.e., $w_{0}=20$ ) and an asymmetric wage distribution with a more productive CBD (with $w_{0}=22$ ). Note that the slightly higher wage at the CBD in the asymmetric case strongly increases the land rent even at the SBDs, and the higher wage reduces the visibility of the SBDs' effects on land rents. 
In addition to the spatial urban equilibrium with an urban core and a mixed-use periphery, other types of spatial equilibria may exist. First, if wages are generally low, living in some areas with high land rents may be unaffordable for workers employed at workplaces located relatively far away. Thus, Equations (5), (9), and (10) must be adjusted. Low wages may reduce the variance in the city's land rents. Second, if wages in the center are low and wages in the SBDs in the outer areas of the city are high and/or if the outer most SBD is close to the city's boundary (i.e., if $N / m-\left\{1+\mathcal{W}\left[-e^{-1-t(b-N / m)}\right]\right\} / t<d_{n}$ ), then the area $\left[0, d_{n}\right]$ may be partially used by farmers.

\section{Concluding remarks}

This paper applied a continuous logit model to a closed, essentially linear polycentric city with a homogenous population and uniform land use. The spatial equilibrium has certain realistic properties that cannot easily be obtained in a standard urban model with deterministic choices. The realistic properties include the following: First, citizens who work in different business centers are incompletely segregated. Second, land rents are generally asymmetric around secondary business districts. Third, only a fraction of the available land may be used by city dwellers in outer areas of the city.

The model presented in this paper is a first step toward a comprehensive analysis of the urban equilibrium within a continuous logit framework. Numerous extensions are possible. First, endogenous land use and non-linear commuting costs should be considered. Second, amenities and externalities should be taken into consideration. These extensions should be pursued in future research. 


\section{References}

Ahlfeldt, G. (2011): "If Alonso was right: modeling accessibility and explaining the residential land gradient," Journal of Regional Science, 51, 318-338.

Alonso, W. (1964): Location and land use: toward a general theory of land rent. Harvard University Press, Cambridge Massachusetts.

AnAs, A. (1990): "Taste heterogeneity and urban spatial structure: the logit model and monocentric theory reconciled," Journal of Urban Economics, 28, 318-335.

AnAs, A., AND I. KIm (1996): "General equilibrium models of polycentric urban land use with endogenous congestion and job agglomeration," Journal of Urban Economics, 40, $232-256$.

Anas, A., AND H.-J. RheE (2006): "Curbing excess sprawl with congestion tolls and urban boundaries," Regional Science and Urban Economics, 36, 510-541.

Ben-Akiva, M., N. Litinas, and K. Tsunokawa (1985): "Continuous spatial choice: the continuous logit model and distributions of trips and urban densities," Transportation Research Part A: General, 19, 119-154.

Ben-Akiva, M., and T. Watanatada (1981): "Application of a continuous spatial choice logit model," in Structural analysis of discrete choice data with econometric applications, ed. by C. F. Manski, and D. McFadden, pp. 320-343. MIT Press, Cambridge, MA.

BRuECKNeR, J. (1987): "The structure of urban equilibria: An integrated treatment of the Muth-Mills model," in Handbook of Regional and Urban Economics, Vol. 2, ed. by E. Mills, pp. 821-845. North-Holland, Amsterdam.

Fujita, M. (1989): Urban economic theory. Cambridge University Press, Cambridge, UK.

Fujita, M., And H. OGawa (1982): "Multiple equilibria and structural transition of nonmonocentric urban configurations," Regional Science and Urban Economics, 12, 161-196. 
Hamilton, B. (1982): "Wasteful commuting," Journal of Political Economy, 90, 10351053.

Lucas, JR., R. E., and E. Rossi-Hansberg (2002): "On the internal structure of cities," Econometrica, 70, 1445-1476.

McFAdden, D. (1976): "The mathematical theory of demand models," in Behavioral travel demand models, ed. by P. Stopher, and A. Meyburg, pp. 305-314. Lexington Books, Lexington, MA.

Mills, E. S. (1967): "An aggregative model of resource allocation in a metropolitan area," American Economic Review, 57, 197-210.

Muth, R. F. (1969): Cities and housing. University of Chicago Press, Chicago.

NG, C. F. (2008): "Commuting distances in a household location choice model with amenities," Journal of Urban Economics, 63, 116-129.

Osland, L., And I. Thorsen (2008): "Effects on housing prices of urban attraction and labor-market accessibility," Environment and Planning A, 40, 2490-2509.

Small, K., And S. Song (1992): "Wasteful commuting: a resolution," Journal of Political Economy, 100, 888-898.

Tscharaktschiew, S., And G. Hirte (2010): "How does the household structure shape the urban economy?," Regional Science and Urban Economics, 40, 498-516.

Van Ommeren, J., and W. Van der Straaten (2005): "Identification of 'wasteful commuting' using search theory," Discussion Paper 05-088/3, Tinbergen Institute Discussion Papers.

Wrede, M. (2009): "A distortive wage tax and a countervailing commuting subsidy," Journal of Public Economic Theory, 11, 297-310.

(2013): "Continuous logit monocentric city model with multiple income classes," Mimeo, FAU Erlangen-Nuremberg. 